\title{
Medication Use as a Contributor to Fluid Overload in the PICU: A Prospective Observational Study
}

\author{
Dana Fuhrman $^{1}$ Kelli Crowley ${ }^{1}$ Carol Vetterly ${ }^{1}$ Keito Hoshitsuki ${ }^{1}$ Alaina Koval ${ }^{1}$ Joseph Carcillo ${ }^{1}$ \\ ${ }^{1}$ Department of Critical Care Medicine, University of Pittsburgh \\ School of Medicine, Pittsburgh, Pennsylvania, United States \\ J Pediatr Intensive Care 2018;7:69-74.

\begin{abstract}
Address for correspondence Dana Fuhrman, DO, MS, Children's Hospital of Pittsburgh of the University of Pittsburgh Medical Center, 4401 Penn Avenue, Children's Hospital Dr. Faculty Pavilion Suite 2000, Pittsburgh, PA 15224, United States

(e-mail: dana.fuhrman@chp.edu).
\end{abstract}

\begin{abstract}
In this prospective observational study, we explored the association of daily fluid intake from medication use with fluid overload in 75 children beginning 24 hours after intubation. The mean percent daily fluid intake from medications was $29 \%$ in the overall

Keywords

- fluid overload

- fluid management

- medication administration cohort. Excess intake and inadequate output contributed significantly to fluid overload. In the 28 patients who became $\geq 10 \%$ fluid overloaded, the mean percent daily fluid intake from medications was $34 \%$, but just $23 \%$ in the patients who did not. Awareness of volume contribution and maximized concentration of parenteral medications when able may lessen the burden of fluid overload.
\end{abstract}

\section{Introduction}

In hemodynamically unstable patients, early and aggressive fluid management is lifesaving. ${ }^{1-3}$ However, after hemodynamic stability has been achieved, many adult and pediatric investigations have shown a significant relationship between positive fluid balance and mortality in critically ill patients. ${ }^{4-14}$ Most authors exploring the effects of fluid overload in children in the intensive care unit (ICU) report a worsening of morbidity and mortality when fluid overload exceeds 10 to $20 \%$ prior to the initiation of continuous renal replacement therapy (RRT). ${ }^{5-9}$

There are numerous factors, including an increased risk for acute kidney injury (AKI), impaired water diuresis, and high volumes of fluid input that put pediatric ICU patients at a particularly high risk for fluid overload. ${ }^{15-17}$ Intravenous (IV) fluids frequently make up a large proportion of an ICU patient's daily fluid intake. ${ }^{18}$ The method most commonly cited for calculating maintenance IV fluid rates in children is extrapolated from the method proposed by Holliday and Segar in the 1950s for calculating the caloric needs in the average hospitalized patient. ${ }^{19} \mathrm{By}$ relating caloric expenditure to water loss, and therefore fluid needs, the $100 / 50 / 20$ or $4 / 2 / 1$ formula is routinely used today. These formulas are not based on the

received

May 10, 2017

accepted after revision

June 24, 2017

published online

July 26, 2017

estimated energy requirements of children in the ICU and can significantly overestimate the fluid needs of critically ill children. Importantly, more recent literature suggests that in an effort to prevent hyponatremia, the volume of IV maintenance fluids obtained with the standard formula proposed by Holliday and Segar should be reduced. ${ }^{20,21}$

Prior studies have investigated the role of continuous RRT in the prevention and treatment of fluid overload. ${ }^{5-10,22,23}$ However, little attention has been given to the contribution of fluid intake in the form of medication administration in the development of fluid overload. Daily scrutiny of fluid volume related to medication intake as well as use of maximally concentrated parenteral medications may serve as to lessen the burden of fluid overload. Therefore, we sought to explore the association of fluid intake from medication administration with fluid overload in a cohort of mechanically ventilated children after the completion of acute resuscitation efforts.

\section{Materials and Methods}

\section{Study Design}

We prospectively obtained fluid intake and output data on all intubated and mechanically ventilated patients during a

Copyright @ 2018 by Georg Thieme Verlag KG, Stuttgart . New York
DOI https://doi.org/ 10.1055/s-0037-1604422. ISSN 2146-4618. 
30-day period (September 16, 2016, through October 15, 2016) in the ICU at the Children's Hospital of Pittsburgh of the University of Pittsburgh Medical Center. In this observational study, all decisions regarding fluid intake were made independently by the clinicians caring for the patients with no involvement of the study team. Patients with a known history of kidney or heart disease were excluded from the analysis. Data collection began 24 hours after intubation, presumably after the acute resuscitation period had concluded, and continued until the time of extubation or until the end of the 30-day period of observation, whichever occurred first. Patients were divided into five age categories: 1 month to 2 years, 3 to 6 years, 7 to 10 years, 11 to 14 years, and 15 to 18 years. AKI was defined based on the Kidney Disease Improving Global Outcomes Criteria (KDIGO) using serum creatinine. ${ }^{24}$ Baseline serum creatinine was defined as the most recent serum creatinine in the past 3 months before hospitalization (if available), including the day of hospital admission. ${ }^{25}$ Patients were deemed to have AKI if they met KDIGO stage 1 or higher. The University of Pittsburgh Quality Improvement Review Committee approved the collection and publication of data for the study.

\section{Statistical Analysis}

Data regarding mean total fluid intake, mean total fluid output, mean total fluid intake exclusively from medication administration, and diuretic use were recorded daily for each patient. Fluid overload was quantified by percentage of fluid overload obtained by the following equation: [(total fluid input at the time of extubation or study conclusion - total fluid output at the time of extubation or study conclusion)/ admission weight $(\mathrm{kg})] \times 100 .^{5}$ Fluid overload was also calculated using a weight-based formula: [(weight at the time of extubation or study conclusion $(\mathrm{kg})$ - weight 24 hours after intubation $(\mathrm{kg})$ )/admission weight $(\mathrm{kg}) \times 100$ ]. Patients were divided based on a fluid overload $<10 \%$ or $\geq 10 \%$. Since polyuria is typically considered to be present when urine output is greater than $2,000 \mathrm{~mL} /$ body surface area/day in children, this was used to define polyuria. ${ }^{26}$ The daily threshold for polyuria was calculated for each patient based on their body surface area. ${ }^{27}$ The chi-square test of independence was used to compare the differences in proportions. Mann-Whitney $U$-tests were completed by age category to compare those who were fluid overloaded to those who were not based on mean daily fluid intake, mean daily fluid output, and mean daily fluid intake from medications. Differences were considered significant if $p<0.05$.

\section{Results}

A total of 75 patients were included in the analysis. The median age was 8 years with a median serum creatinine of $0.40 \mathrm{mg} / \mathrm{dL}$ (-Table 1). The median body mass index (BMI) and BMI percentile were $18.8 \mathrm{~kg} / \mathrm{m}^{2}$ and 85.0 , respectively. Seizures and pneumonia were the two most common reasons for admission. Patients were followed up for a mean number of 6.9 days. Fluid overload $\geq 10 \%$ occurred in 28 (37\%) of the patients observed using the fluid overload percent
Table 1 Baseline information of all mechanically ventilated patients during a 30-day period in a 36-bed academic PICU

\begin{tabular}{|l|l|}
\hline Characteristics & $\begin{array}{l}\text { Median (interquartile } \\
\text { range) or } \boldsymbol{n}(\%)\end{array}$ \\
\hline Age (y) & $8(2-15)$ \\
\hline Male & $56(42)$ \\
\hline Height (cm) & $118.5(81.0-152.4)$ \\
\hline Weight (kg) & $25.4(12.7-50.0)$ \\
\hline BMI (kg/m $\left.{ }^{2}\right)$ & $18.8(15.3-24.7)$ \\
\hline BMI percentile ${ }^{\text {a }}$ & $85.0(15.8-95.5)$ \\
\hline $\begin{array}{l}\text { Baseline serum creatinine } \\
\text { (mg/dL) }\end{array}$ & $0.40(0.26-0.69)$ \\
\hline Reason for admission & \\
\hline Seizures & $13(17.3)$ \\
\hline Pneumonia & $12(16)$ \\
\hline Trauma & $8(10.6)$ \\
\hline Sepsis & $9(12)$ \\
\hline Traumatic brain injury & $7(9.3)$ \\
\hline ENT procedure & $5(6.7)$ \\
\hline Acute abdomen & $4(5.3)$ \\
\hline Toxic ingestion & $4(5.3)$ \\
\hline Liver failure & $3(4.0)$ \\
\hline Status asthmaticus & $3(4.0)$ \\
\hline Encephalitis & $2(2.6)$ \\
\hline Meningitis & $2(2.6)$ \\
\hline Brain mass resection & $1(1.3)$ \\
\hline Intussusception & $1(1.3)$ \\
\hline Pulmonary edema & $1(1.3)$ \\
\hline & \\
\hline
\end{tabular}

Abbreviations: BMI, body mass index; PICU, pediatric intensive care unit. ancluding all patients 2 years of age and older.

equation to calculate fluid overload and in 24 (32\%) of the patients using the weight-based formula. In the overall patient cohort, $29 \%$ of the mean daily fluid intake was attributed to medication intake. The mean daily percent fluid intake from medications alone was no less than $19 \%$ for all age groups with a range of 19 to $39 \%$ (-Table 2). The proportion of patients with a mean fluid intake that exceeded the definition for polyuria was the largest in the youngest patients with $84 \%$ of patients in the 1-month to 2 year-old age group having a mean daily fluid intake that was greater than their threshold for polyuria.

Using the fluid overload percent equation, $\geq 10 \%$ fluid overload occurred across all age groups, with the highest proportion in the 1-month to 2-year-old patients (-Table 2). In the 28 patients who became $\geq 10 \%$ fluid overloaded, the mean percent daily fluid intake from medications was $34 \%$. In contrast, in the patients whose fluid status did not reach $10 \%$, the mean percent fluid intake from medications was $23 \%$. Although the mean percent fluid intake from medications 
Medication Use as a Contributor to Fluid Overload in the PICU Fuhrman et al. 71

Table 2 Contribution of fluid intake by medications in all mechanically ventilated patients during a 30-day period in a 36-bed academic PICU

\begin{tabular}{|c|c|c|c|c|c|c|c|c|}
\hline Age & $\begin{array}{l}\text { Mean no. } \\
\text { of days } \\
\text { observed } \\
\text { per } \\
\text { patient }\end{array}$ & $\begin{array}{l}\text { Fluid } \\
\text { overload }\end{array}$ & $N$ & $\begin{array}{l}\text { Mean total } \\
\text { fluid } \\
\text { intake per } \\
24 \mathrm{~h}^{\mathrm{a}}\end{array}$ & $\begin{array}{l}\text { Mean total } \\
\text { fluid output } \\
\text { per } 24 \mathrm{~h}^{\mathrm{a}}\end{array}$ & $\begin{array}{l}\text { Mean fluid } \\
\text { intake from } \\
\text { medications } \\
\text { only per } \\
24 \mathrm{~h}^{\mathrm{a}}\end{array}$ & $\begin{array}{l}\text { Mean daily \% } \\
\text { intake from } \\
\text { medications } \\
\text { only }\end{array}$ & $\begin{array}{l}\% \text { of patients } \\
\text { with a mean } \\
\text { daily fluid } \\
\text { intake } \\
>\text { polyuria }\end{array}$ \\
\hline \multirow[t]{3}{*}{$1 \mathrm{mo}-2 \mathrm{y}$} & 7.6 & & 25 & 968 & 819 & 184 & 19 & 84 \\
\hline & & $\geq 10 \%$ & 13 & $880^{\mathrm{b}}$ & $685^{b}$ & 190 & 22 & 92 \\
\hline & & $<10 \%$ & 12 & $1,113^{b}$ & $1,038^{b}$ & 176 & 16 & 75 \\
\hline \multirow[t]{3}{*}{$3-6 y$} & 6.2 & & 12 & 1,587 & 1,358 & 461 & 29 & 67 \\
\hline & & $\geq 10 \%$ & 4 & 1,645 & 1,355 & 510 & 31 & 100 \\
\hline & & $<10 \%$ & 8 & 1,475 & 1,362 & 418 & 28 & 50 \\
\hline \multirow[t]{3}{*}{$7-10 y$} & 4 & & 6 & 1,574 & 1,187 & 414 & 26 & 33 \\
\hline & & $\geq 10 \%$ & 2 & $2,167^{b}$ & $1,631^{b}$ & $678^{b}$ & 31 & 100 \\
\hline & & $<10 \%$ & 4 & $1,029^{b}$ & $744^{\mathrm{b}}$ & $172^{b}$ & 17 & 0 \\
\hline \multirow[t]{3}{*}{$11-14 y$} & 10.9 & & 9 & 2,017 & 1,843 & 785 & 39 & 33 \\
\hline & & $\geq 10 \%$ & 4 & $1,881^{b}$ & $1,711^{b}$ & 769 & 41 & 25 \\
\hline & & $<10 \%$ & 5 & $2,462^{b}$ & $2,272^{b}$ & 758 & 31 & 40 \\
\hline \multirow[t]{3}{*}{$15-18 y$} & 5.9 & & 23 & 2,609 & 2,063 & 735 & 28 & 22 \\
\hline & & $\geq 10 \%$ & 5 & 2,810 & 1,734 & $1,066^{\mathrm{b}}$ & 38 & 20 \\
\hline & & $<10 \%$ & 18 & 2,416 & 2,029 & $554^{b}$ & 23 & 22 \\
\hline
\end{tabular}

Abbreviation: PICU, pediatric intensive care unit.

${ }^{a}$ Milliliters.

bignificant difference comparing fluid overload status ( $\geq 10$ vs. $<10 \%$ ) within each age group at the 0.05 probability level.

was lower in the patients whose fluid status did not reach $10 \%$, this difference was not statistically significant $(p=0.30)$. Too much fluid intake and not enough fluid output contributed significantly to whether or not patients experienced $\geq 10 \%$ fluid overload. For example, when comparing the $<10 \%$ fluid overload group to the $\geq 10 \%$ fluid overload group in patients 1 month to 2 years of age, both the daily mean total fluid intake $(p<0.001)$ and output $(p<0.001)$ were significantly lower in the $\geq 10 \%$ group, suggesting that less output was contributing to the development of fluid overload in this patient group. This also occurred when comparing the fluid overload status of children in the 11- to 14-year-old age group (total fluid intake [ $p<0.001$ ]; total fluid output [ $p=0.02]$ ). In contrast, in the 7 - to 10-year-old age group, both the mean fluid intake $(p<0.001)$ and output $(p<0.001)$ were significantly greater in the $\geq 10 \%$ fluid overload group, suggesting that more intake (rather than less output) was contributing to fluid overload in these patients. It was in this age group $(p<0.001)$ and the 15- to 18-year-old age group $(p=0.04)$ that the mean proportion of fluid intake from medications was significantly greater in the $\geq 10 \%$ fluid overload group.

The overall incidence of AKI in the study cohort was $18.7 \%$. The AKI incidence was the highest in the 11- to 14-year-old age group (55.6\%; - Table 3). The incidence of AKI in patients who were $\geq 10 \%$ fluid overloaded was $17.9 \%$ and it was $19.1 \%$ in those who were $<10 \%$ fluid overloaded. This difference was not statistically significant $(p=0.89$ ).

Of the 75 patients observed, $47.3 \%$ of patients received a diuretic. Of the 28 patients who were $\geq 10 \%$ fluid overloaded, 20 patients (71\%) were given a diuretic at some point during the observation period. For seven patients who became $\geq 20 \%$ fluid overloaded, five of these patients did not receive a diuretic during the observation period. Only two patients who received a diuretic became $\geq 20 \%$ fluid overloaded.

Table 3 Baseline serum creatinine and AKI incidence by age group

\begin{tabular}{|l|l|l|}
\hline Age & $\begin{array}{l}\text { Median baseline } \\
\text { serum creatinine } \\
\text { (interquartile }^{\text {range) }}\end{array}$ & AKI incidence (\%) \\
\hline 1 mo-2 y & $0.20(0.15-0.32)$ & 20.0 \\
\hline $3-6$ y & $0.26(0.20-0.28)$ & 16.7 \\
\hline $7-10$ y & $0.42(0.30-0.44)$ & 0 \\
\hline $11-14$ y & $0.48(0.29-0.71)$ & 55.6 \\
\hline $15-18$ y & $0.71(0.39-0.95)$ & 17.3 \\
\hline
\end{tabular}

Abbreviation: AKI, acute kidney injury.

${ }^{\mathrm{a}} \mathrm{mg} / \mathrm{dL}$. 


\section{Discussion}

Fluid overload $\geq 10 \%$ was common among our cohort of patients, occurring in $37 \%$ of mechanically ventilated patients over a 30-day observation period based on percent fluid balance. We obtained a similar proportion of fluid overload (32\%) using a weight-based formula, which is consistent with prior investigations that have compared percent fluid balance to weight-based formulas for calculating fluid overload. $^{9}$ There was no significant difference in AKI incidence when comparing patients who became $\geq 10 \%$ fluid overloaded to those who did not. Therefore, it does not appear in our overall study cohort that fluid overload represented a reduced renal function as a result of AKI. Interestingly, the two patient groups ( 1 month to 2 years and 1114 years) who had the highest incidence of AKI ( - Table 3 ) also had a decreased fluid output which appeared to contribute to the development of fluid overload (-Table 2 ).

Both too much fluid intake, with medications potentially playing a role, and inadequate fluid output appeared to contribute markedly to the fluid overload. The proportion of fluid intake with medications was greater in the group that became $\geq 10 \%$ fluid overloaded. Given the known negative consequences of fluid overload shown in previous studies, it is important to consider potential changes in practice for the prevention of excess fluid accumulation in critically ill children. Notably, given the results of this analysis, an increased attention to the volume of fluids given with medications is important in the prevention of fluid overload in critically ill children after the acute phase of illness. The Food and Drug Administration, through the Safe Use Initiative, has been working in conjunction with pharmacy and safety organizations including the American Society of Health-Systems Pharmacists, the Pediatric Pharmacy Association, the Institute for Safe Medication Practices, and the Association for the Advancement of Medical Instrumentation to encourage the development of standardized concentrations and dosing units for continuous infusions. ${ }^{28}$ While the guiding principles of this project include a recommendation to limit to one standard concentration for infusions when possible, it is stated that there is an understanding that two or three concentrations might be necessary especially when considering fluid status and individual patient needs. In the ICU, a physician may not perceive the large proportion of IV fluid intake that is being given with medications, an important modifiable risk factor in avoiding fluid overload.

Our youngest patient group ( 1 month to 2 years) had the highest proportion of patients with a mean fluid intake who exceeded their definition of polyuria and also the highest proportion of patients who became fluid overloaded. This patient group may represent a particularly vulnerable population for the development of fluid overload and would benefit from the careful attention to fluid intake. In a multicenter study done by the RRT investigators, it was demonstrated that IV fluids make up $86 \%$ and enteral nutrition makes up less than $10 \%$ of daily fluid intake on day 3 of a pediatric ICU stay. ${ }^{18}$ Given that humidification during spon- taneous respiration accounts for a proportion of daily insensible losses, patients requiring mechanical ventilation will have less daily insensible losses when compared with those breathing spontaneously. ${ }^{29}$ Total fluid intake should account for all measurable output, including urine, gastrointestinal and bleeding losses, as well as an understanding of a patient's estimated insensible losses. Formulas, such as the one given by Holliday-Segar, are not based on the energy expenditure of critically ill patients. ${ }^{19}$

There should be close attention to a patient's nutritional needs early in the ICU stay, recognizing that typical crystalloid fluids do not provide adequate nutrition. Given that prior investigations have shown an association of adverse outcomes and inadequate caloric intake, the use of total parenteral nutrition (TPN) and enteral feeds should be considered with careful attention not to restrict feeds or TPN based on a desire to avoid fluid overload. ${ }^{30-32}$ When nutritional support is being compromised due to worsening volume overload, the initiation of diuretic therapy or RRT should be strongly considered.

Almost half of the ventilated patients in our ICU were given diuretics at some point during their intubation course. Not surprisingly, of the 28 patients who were $\geq 10 \%$ fluid overloaded, 20 (71\%) patients were started on diuretics. Interestingly, of these 20 patients, only 2 (10\%) became $\geq 20 \%$ fluid overloaded. This suggests that the initiation of diuretics may have prevented the progression of fluid overload in patients who were already $\geq 10 \%$ fluid overloaded. ${ }^{33,34}$ However, importantly, diuretic use in critically ill adults has been shown to be associated with a lack of renal recovery and an increased risk of death. ${ }^{35}$ The decision to initiate diuretic therapy should not be based solely on positive fluid status, but should be considered after carefully taking into consideration ways to limit fluid intake as well as a patient's renal function.

Given the negative consequences of fluid overload in the pediatric ICU, it is important that once capillary leak has sealed off, close attention to fluid administration begins. Given the relatively large contribution of IV fluids to fluid overload as evidenced in our ICU and prior studies, ${ }^{18}$ it is important that efforts are made to minimize IV fluid administration when appropriate. Fluid congestion and elevated venous pressures can result in decreased renal blood flow and glomerular filtration rate. ${ }^{36}$ Therefore, continuing to provide increasing volumes of IV fluids to a patient who is hypotensive, for example, due to sedative or analgesic medications, can have detrimental consequences. The consideration of the early initiation of vasoactive agents, such as a norepinephrine infusion, has been shown to have significant improvements in renal perfusion along with mean arterial pressure. ${ }^{37}$

We acknowledge important limitations in this study. Given the single-center nature of our study, the findings may be center specific and not be generalizable to other pediatric ICUs. We followed up patients for 30 days, discontinuing data collection in some patients prior to the discontinuation of mechanical ventilation, potentially missing opportunities for capturing more fluid overloaded patients. Our relatively small sample size may have limited the power of the study to detect a statistically significant difference in mean percent fluid intake 
from medications in those who were or were not fluid overloaded. No patients died during our study period; however, we did not specifically investigate outcomes associated with fluid overload, although this has been explored in other investigations. ${ }^{5-9}$ We calculated the fluid balance beginning 24 hours after intubation using the standard formula (including admission weight) to specifically examine the contribution of fluid intake from medications after the acute resuscitation period. This may have led to an overestimation of fluid overload, given that the admission weight was obtained presumably before or during the acute resuscitation period. It is also possible that some patients continued to require resuscitation after this 24hour period.

In conclusion, it may be prudent for institutions to develop a drug library subset containing maximum concentrations reserved for those patients who are or are likely to become fluid overloaded and require restriction of fluid intake. Antimicrobial agents, electrolyte boluses, and other medications diluted in the minimal amount of fluid that can be administered safely should be included. The appropriate use of protocols for maximally concentrated medications when able is an important factor in avoiding fluid overload. We should be devoting the same attention to fluid balance when patients become hemodynamically stable as we do to fluid administration during the acute phase of illness. Patients should not automatically be placed on IV fluids according to weight-based estimates. As a result of the negative sequelae of fluid overload, percent fluid overload should be tracked daily during admission. The volume of fluids given in medications should be included in the daily assessment of fluid status, given that this can account for a significant proportion of fluid intake. Efforts should be made whenever possible to utilize the maximal concentrations of parenteral medications in patients receiving daily volumes greater than their polyuria threshold. Given the high fluid demands of the pediatric ICU, the initiation of diuretic therapy or RRT should be discussed frequently as fluid status is followed closely.

\section{References}

1 Rivers E, Nguyen B, Havstad S, et al; Early Goal-Directed Therapy Collaborative Group. Early goal-directed therapy in the treatment of severe sepsis and septic shock. N Engl J Med 2001;345(19): 1368-1377

2 Carcillo JA, Davis AL, Zaritsky A. Role of early fluid resuscitation in pediatric septic shock. JAMA 1991;266(09):1242-1245

3 Han YY, Carcillo JA, Dragotta MA, et al. Early reversal of pediatricneonatal septic shock by community physicians is associated with improved outcome. Pediatrics 2003;112(04):793-799

4 Acheampong A, Vincent JL. A positive fluid balance is an independent prognostic factor in patients with sepsis. Crit Care 2015; 19:251

5 Goldstein SL, Currier H, Graf Cd, Cosio CC, Brewer ED, Sachdeva R. Outcome in children receiving continuous venovenous hemofiltration. Pediatrics 2001;107(06):1309-1312

6 Goldstein SL, Somers MJ, Baum MA, et al. Pediatric patients with multi-organ dysfunction syndrome receiving continuous renal replacement therapy. Kidney Int 2005;67(02):653-658

7 Foland JA, Fortenberry JD, Warshaw BL, et al. Fluid overload before continuous hemofiltration and survival in critically ill children: a retrospective analysis. Crit Care Med 2004;32(08):1771-1776
8 Hayes LW, Oster RA, Tofil NM, Tolwani AJ. Outcomes of critically ill children requiring continuous renal replacement therapy. J Crit Care 2009;24(03):394-400

9 Sutherland SM, Zappitelli M, Alexander SR, et al. Fluid overload and mortality in children receiving continuous renal replacement therapy: the prospective pediatric continuous renal replacement therapy registry. Am J Kidney Dis 2010;55(02): 316-325

10 Selewski DT, Cornell TT, Lombel RM, et al. Weight-based determination of fluid overload status and mortality in pediatric intensive care unit patients requiring continuous renal replacement therapy. Intensive Care Med 2011;37(07):1166-1173

11 Li Y, Wang J, Bai Z, et al. Early fluid overload is associated with acute kidney injury and PICU mortality in critically ill children. Eur J Pediatr 2016;175(01):39-48

12 Boyd JH, Forbes J, Nakada TA, Walley KR, Russell JA. Fluid resuscitation in septic shock: a positive fluid balance and elevated central venous pressure are associated with increased mortality. Crit Care Med 2011;39(02):259-265

13 Abulebda K, Cvijanovich NZ, Thomas NJ, et al. Post-ICU admission fluid balance and pediatric septic shock outcomes: a risk-stratified analysis. Crit Care Med 2014;42(02):397-403

14 de Oliveira FS, Freitas FG, Ferreira EM, et al. Positive fluid balance as a prognostic factor for mortality and acute kidney injury in severe sepsis and septic shock. J Crit Care 2015;30(01):97-101

15 Ellison DH, Berl T. Clinical practice. The syndrome of inappropriate antidiuresis. N Engl J Med 2007;356(20):2064-2072

16 Andreoli SP. Acute renal failure. Curr Opin Pediatr 2002;14(02): 183-188

17 Hui-Stickle S, Brewer ED, Goldstein SL. Pediatric ARF epidemiology at a tertiary care center from 1999 to 2001. Am J Kidney Dis 2005;45(01):96-101

18 Bellomo R, Cass A, Cole L, et al; RENAL Replacement Therapy Study Investigators. An observational study fluid balance and patient outcomes in the Randomized Evaluation of Normal vs. Augmented Level of Replacement Therapy trial. Crit Care Med 2012;40(06): 1753-1760

19 Holliday MA, Segar WE. The maintenance need for water in parenteral fluid therapy. Pediatrics 1957;19(05):823-832

20 Peruzzo M, Milani GP, Garzoni L, et al. Body fluids and salt metabolism - part II. Ital J Pediatr 2010;36(01):78

21 Friedman A. Fluid and electrolyte therapy: a primer. Pediatr Nephrol 2010;25(05):843-846

22 Flores FX, Brophy PD, Symons JM, et al. Continuous renal replacement therapy (CRRT) after stem cell transplantation. A report from the prospective pediatric CRRT Registry Group. Pediatr Nephrol 2008;23(04):625-630

23 Gulla KM, Sachdev A, Gupta D, Gupta N, Anand K, Pruthi PK. Continuous renal replacement therapy in children with severe sepsis and multiorgan dysfunction - a pilot study on timing of initiation. Indian J Crit Care Med 2015;19(10):613-617

24 Kidney Disease Improving Global Outcomes (KDIGO) Work Group. KDIGO clinical practice guidelines for acute kidney injury. Kidney Int Suppl 2012;2:1138

25 Sutherland SM, Byrnes JJ, Kothari M, et al. AKI in hospitalized children: comparing the pRIFLE, AKIN, and KDIGO definitions. Clin J Am Soc Nephrol 2015;10(04):554-561

26 Saborio P, Tipton GA, Chan JC. Diabetes insipidus. Pediatr Rev 2000;21(04):122-129, quiz 129

27 Du Bois D, Du Bois EF. A formula to estimate the approximate surface area if height and weight be known. 1916. Nutrition 1989; 5(05):303-311, discussion 312-313

28 Expert Panel on Adult Continuous Infusions. ASHP Standardize for Safety Initiative. Available at: https://www.ashp.org/Pharmacy Practice/Standardize-4- Safety-Initiative/Initiative-Overview. Accessed April 24, 2017

29 Bruck E. Water in expired air: physiology and measurement. J Pediatr 1962;60:869-881 
74 Medication Use as a Contributor to Fluid Overload in the PICU Fuhrman et al.

30 Sabatino A, Regolisti G, Maggiore U, Fiaccadori E. Protein/energy debt in critically ill children in the pediatric intensive care unit: acute kidney injury as a major risk factor. J Ren Nutr 2014;24(04): 209-218

31 Toole BJ, Toole LE, Kyle UG, Cabrera AG, Orellana RA, Coss-Bu JA. Perioperative nutritional support and malnutrition in infants and children with congenital heart disease. Congenit Heart Dis 2014 $9(01): 15-25$

32 Kleiber M. Joules vs. calories in nutrition. J Nutr 1972;102(03): 309-312

33 Martin GS, Mangialardi RJ, Wheeler AP, Dupont WD, Morris JA, Bernard GR. Albumin and furosemide therapy in hypoproteinemic patients with acute lung injury. Crit Care Med 2002;30(10): 2175-2182
34 Wiedemann HP, Wheeler AP, Bernard GR, et al; National Heart, Lung and Blood Institute Acute Respiratory Distress Syndrome (ARDS) Clinical Trials Network. Comparison of two fluid-management strategies in acute lung injury. N Engl J Med 2006;354(24):2564-2575

35 Mehta RL, Pascual MT, Soroko S, Chertow GM; PICARD Study Group. Diuretics, mortality, and nonrecovery of renal function in acute renal failure. JAMA 2002;288(20):2547-2553

36 Doty JM, Saggi BH, Sugerman HJ, et al. Effect of increased renal venous pressure on renal function. J Trauma 1999;47(06): 1000-1003

37 Piva J, Alquati T, Garcia PC, Fiori H, Einloft P, Bruno F. Norepinephrine infusion increases urine output in children under sedative and analgesic infusion. Rev Assoc Med Bras (1992) 2014;60(03):208-215 